\title{
For Want of the Right Letter the Child Was Lost ... Almost
}

\author{
Patrick McDonald
}

Can. J. Neurol. Sci. 2009; 36: 791-792

\begin{abstract}
For want of a nail, The shoe was lost. For want of a shoe, The horse was lost. For want of a horse, The rider was lost. For want of a rider, The battle was lost. For want of a battle, The kingdom was lost. And all for the want, Of a horshoe nail.
\end{abstract}

As a pediatric neurosurgeon, I see many children with benign incidental findings on neuroimaging. Surprisingly, these visits often take more time than those outlining the treatment plan for a child with a malignant brain tumour. Families arrive knowing "there's a problem with the brain scan" and usually nothing

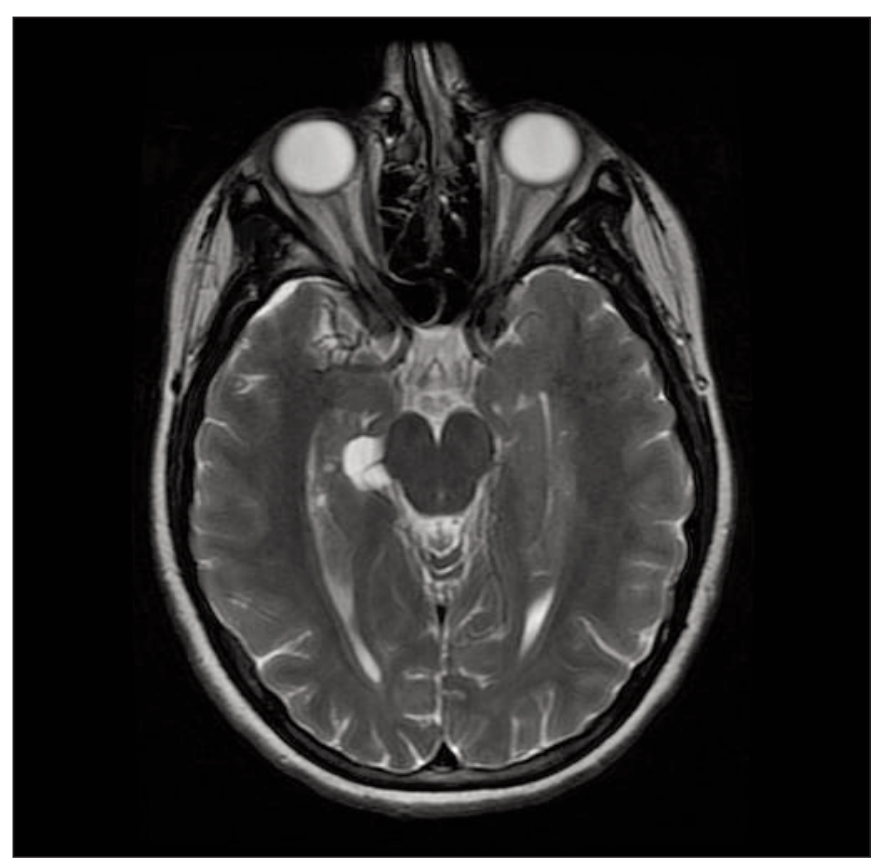

Figure 1: T2-weighted axial MR showing a right temporal cyst in the region of the choroidal fissure. more. The anxiety of that unknown is difficult to assuage with a simple "nothing to worry about- see you later". A typographical error on a recent written MRI report showed me how powerful that fear of the unknown can be.

Amy (not her real name), a 14 year-old-girl, was sent to see me after an MRI of the brain was done for persistent headaches after a mild head injury. I always look at the imaging before deciding when to see the patient- urgently or in the next elective spot. Amy's MR showed a small right sided cyst in the region of the choroidal fissure- some call these choroid cysts (see Figure 1). These are benign spinal fluid filled cysts and rarely require treatment. I booked Amy into an open clinic spot the following month.

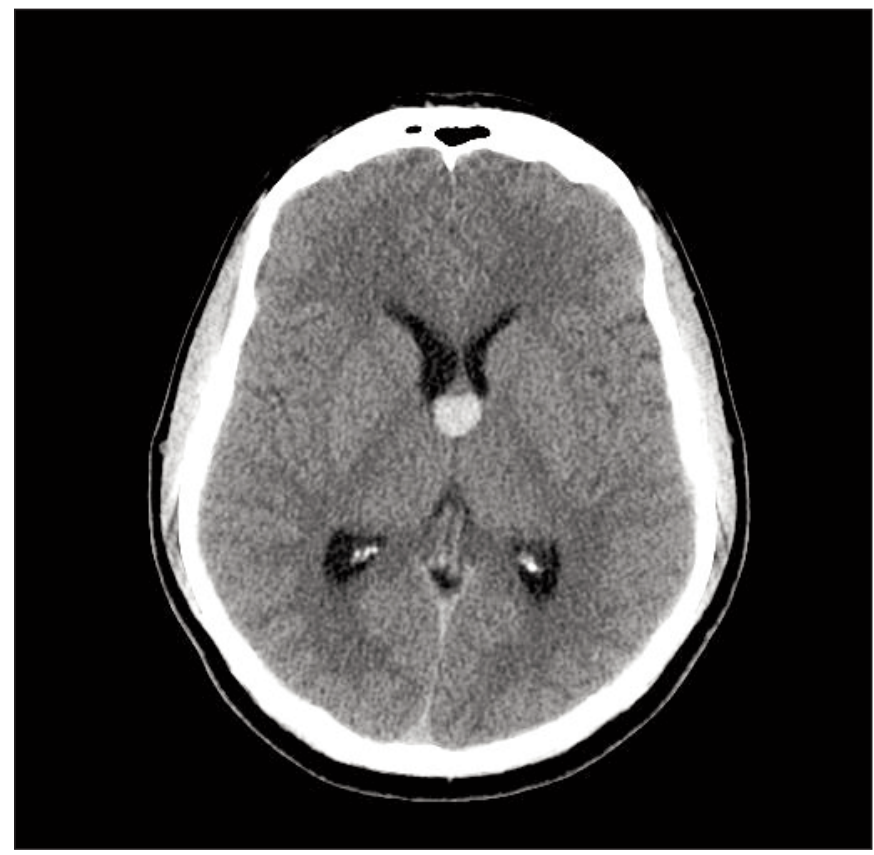

Figure 2: Axial CT scan showing colloid cyst of the third ventricle.

From the Section of Neurosurgery, Winnipeg Children's Hospital, University of Manitoba, Winnipeg, Manitoba, Canada.

ReCeived June 8, 2009. Final Revisions Submitted June 16, 2009.

Correspondence to: Patrick McDonald, Section of Neurosurgery, Winnipeg Children's Hospital, GB-126 820 Sherbrook Street, Winnipeg, Manitoba, R3M 0J9, Canada. 
By the time I saw Amy, her headaches were gone and her neurologic exam was completely normal. I showed Amy and her mother the MRI, stating "you were probably born with this. It's just a co-incidence that it was picked up. It's very unlikely it will ever cause you problems. I'm glad your headaches are betterany questions?"

Amy's mother was clearly angry. Ashen-faced, she blurted "you mean she's not going to die?".

"Not from this", I replied. Mom sat down, tears streaming down her cheeks- they weren't tears of relief. I wasn't quite sure what had just happened. After some coaxing, I was informed that the family had been told that this lesion could cause a "blockage" in the brain, and if not dealt with immediately, Amy could die suddenly- even in her sleep. Amy's friends and teachers had been told to watch for any changes and call an ambulance immediately if anything seemed out of the ordinary. For the past month Amy's mother had spent sleepless nights checking hourly on her daughter, wondering if she would be alive in the morning.

I excused myself and went to re-read Amy's chart to see if it had any explanation for what had just happened. At the bottom of her written MRI report I found the answer. Although the narrative report described a cyst located near the choroidal fissure, the final diagnosis read colloid cyst. Colloid cysts (see Figure 2), although benign tumours of the third ventricle, can suddenly obstruct the flow of cerebrospinal fluid at the level of the foramen of Munro, and cause acute hydrocephalus. Sudden death, although rare, can happen with colloid cysts. For whatever reason, an $l$ had been substituted for an $r$. The letter from the referring physician restated the typo found in the MR report. I had read the referral letter and the MR report before looking at the images myself, but the potential seriousness of the mix-up had not occurred to me.
I returned to the exam room, explaining the mistake in the report and stressing that Amy did not have a colloid cyst. To reassure everyone (myself included), I offered to repeat the MRI in six months and see the family again when it was done. At the end of the visit, everyone was smiling and happy but that was not to last. Amy herself seemed nonplussed by it all.

I had spent most of my time reassuring Amy's mom, not realizing the effects of the typographical error on Amy herself. Already an anxious young woman, the fear of going to bed and never waking up again became a trigger for psychiatric problems. Over the next months, Amy was hospitalized for a major depressive illness. When I saw her again six months later, she had just been released from the pschyiatric ward. Healed slash marks on her wrists signalled a suicide attempt. Although the repeat MRI showed no change in the cyst, the same couldn't be said for Amy.

I read my dictated letters a lot more closely now before signing them. A typographical error or a word misheard by a typist can set in motion an unanticipated chain of events with devastating consequences.

I had always known the power of words in medicine. Cancer, tumour, malignant. They all conjure images of death, pain and suffering. Never before had I seen the power of a single letter. $L$ for $r$. It was almost the difference between life and death. 